Susan Broomhall, ed.

Ordering Emotions in Europe, 110o-180o. Leiden: Brill, 2015. Pp. 319. Hb, €126.

In the last few years, the rapidly maturing field of studies of medieval and early modern emotions has greatly benefited from the collaborative effort of the Australian Research Council Centre of Excellence for the History of Emotions at the University of Western Australia. This volume is a fine and fitting product of their collective endeavor. It forcefully moves away from the sterile distinction often made in research between the normative efforts of arranging and regulating emotions and the actual practices of lived emotions To the contrary, the volume argues that the considerable attention to emotions in contemporary treatises, literary texts, visual representations and written testimonies reflect, but also steer the everyday reality of emotions in people's lives. The main emphasis in the volume is on moral, ethical, and religious perspectives raised by emotional concerns. The binding dynamic of the volume, well articulated by the editor in the introduction, is that individuals ordered their emotions in everyday life because it helped them connect to society and its moral values. Pervasive in the volume is attention to the gendering of discourses. Topics range from twelfth- and thirteenth-century Scholastic thinking on the supernatural and on masculinity to medieval theories on the emotional effects of music, and Christine de Pizan's conceptions of family relations and female experiences. For the late medieval and early modern period, grief, compassion, anxiety, jealousy, fear of demons, and fears of patients are all analyzed through compelling case studies. Two contributions specifically deal with Jesuit writings, both dealing with love, affection, gender, and friendship.

Raphaële Garrod analyzes how Francisco Suárez and Nicolas Caussin conceptualized maternal love as a contingent experience (involving much suffering, pain, and grief) that paralleled eschatological perspectives. Prescribing maternal love as charity (involving among other things the acceptance of personal grief), both Jesuits argued for the intellectual foundations of maternal emotion, channeling emotional energy toward overcoming the natural condition of maternal despair and turning it into spiritual longing for the afterlife. In intellectual terms, this raises important questions about the use of Stoic thought by authors like Suárez and Caussin. Garrod discusses these on the basis of their texts and accepts that such discussions contributed to the porousness of the boundaries between supposedly oppositional thought systems. Her suggestion is that this conceptual eclecticism contributed to the effectiveness of the eschatological prescriptions. Yasmin Haskell points out how adolescents in French Jesuit schools at the turn of the eighteenth century adroitly learned to place themselves in the position of somebody else entirely through Latin 
didactic poetry. As an offshoot, this fueled their friendships and strengthened their sense of belonging to a community. The pupils practiced, pace Haskell, an imaginative understanding of others through the emotional repertoire of historical and contemporary examples of perseverance. The emphasis seems to be on the practice of friendship and much less on martyrdom, a major theme in that other great genre of Latin education, school drama. Indeed, it seems that in the classroom more than on the stage a more free emotional repertoire could be experimented. That repertoire emphatically included one's own experiences and imaginations. How this related to emotion management by the boys on the stage is as of yet unclear.

The volume calls for further attention to the impact of emotions on wide audiences. It concentrates, for instance, on texts used in pastoral care and, inversely, brings in the voices of medical patients and victims of inquisitors. But overall, it seems clear that, however wide, these audiences were mainly elite: the kind of documents studied are learned treatises and, regrettably but unavoidably, mostly elite responses are documented. In one respect these essays demonstrate that the claims of intellectual history to be relevant to the minute emotional dealings of everyday life can be substantiated. We learn that female audiences are implicated in the structure and topical content of the writings studied and that occasional female patrons occur. Similarly, but to a lesser extent, male gendering comes into view; in a few cases, family concerns are considered. What always strikes the reader in such studies is that emotions of fear, anxiety, anger, and desperation seem to have moved pens more quickly and more penetratingly. The editor is therefore to be credited that hope and love receive their due in this collection.

Although innovative in their reading of how lived emotions have permeated textual discourses, the volume's contributions on the Middle Ages are primarily concerned with established Christian rubrics and canonical authors (with the possible exception of the nuanced essay on the hardly known and little studied treatise on consolation of Nicholas de Korto, bishop of Modrus in the fifteenth century). By contrast, the slightly larger early modern section (seven out of the thirteen essays) of the collection deals with a very broad range of voices, few of which were major intellectual authorities of their day. The early modern section shifts the emphasis to a probing of how people in ordinary circumstances made sense of the prescriptions and advice literature they encountered. But such a reception study has its own methodological difficulties, which are not always resolved in the essays. The essay on patient-physician correspondence deals almost entirely with patients' narratives, with hardly any attention to what sense their physicians made of this. The issue of ordering emotions thus seems to become blurred as one moves into the early 
modern period. Institutions, rather than authors and texts, seem to matter more when it comes to streamlining the passions, whether charitable organizations or Jesuit schools. The excellent suggestions concerning Catholic contexts (four out of the seven essays on the early modern period) cause some regret that Protestant contexts are not detailed in similar ways. For the medieval period, on the other hand, a fuller view is given of the emotional implications of considering the world — as well as life after death — through the lens of educational texts that stand in a firm relationship with Christian theology. Obviously and fortunately, there is still work to be done understanding the relations between religion, ethics, and personal emotions, and this volume looks in the right direction.

\section{Johan Verberckmoes}

KU Leuven

johan.verberckmoes@kuleuven.be

DOI 10.1163/22141332-00402008-09 